\title{
Effects on patients with asthma of eradicating visible indoor mould: a randomised controlled trial
}

\author{
M L Burr, I P Matthews, R A Arthur, H L Watson, C J Gregory, F D J Dunstan, S R Palmer
}

Thorax 2007;62:767-772. doi: 10.1136/thx.2006.070847

See end of article for authors' affiliations

Correspondence to: Dr M L Burr, Department of Epidemiology, Statistics and Public Health, Neuadd Meirionnydd, Heath Park, Cardiff CF14 4YS, UK: burrml@cf.ac.uk

Received 24 August 2006 Accepted 27 February 2007
Background: It is not clear whether associations between respiratory symptoms and indoor mould are causal. A randomised controlled trial was conducted to see whether asthma improves when indoor mould is removed.

Methods: Houses of patients with asthma were randomly allocated into two groups. In one group, indoor mould was removed, fungicide was applied and a fan was installed in the loft. In the control group, intervention was delayed for 12 months. Questionnaires were administered and peak expiratory flow rate was measured at baseline, 6 months and 12 months.

Results: Eighty-one houses were allocated to the intervention group and 83 to the control group; 95 participants in 68 intervention houses and 87 in 63 control houses supplied follow-up information. Peak expiratory flow rate variability declined in both groups, with no significant differences between them. At 6 months, significantly more of the intervention group showed a net improvement in wheeze affecting activities (difference between groups $25 \%, 95 \% \mathrm{Cl} 3 \%$ to $47 \% ; \mathrm{p}=0.028$ ), perceived improvement of breathing $(52 \%, 95 \% \mathrm{Cl} 30 \%$ to $74 \% ; \mathrm{p}<0.0001)$ and perceived reduction in medication $159 \%, 95 \% \mathrm{Cl} 35 \%$ to $81 \% ; \mathrm{p}<0.0001)$. By 12 months the intervention group showed significantly greater reductions than the controls in preventer and reliever use, and more improvement in rhinitis $(24 \%, 95 \% \mathrm{Cl} 9 \%$ to $39 \% ; \mathrm{p}=0.001)$ and rhinoconjunctivitis $(20 \%, 95 \% \mathrm{Cl} 5 \%$ to $36 \% ; \mathrm{p}=0.009)$.

Conclusions: Although there was no objective evidence of benefit, symptoms of asthma and rhinitis improved and medication use declined following removal of indoor mould. It is unlikely that this was entirely a placebo effect. l ndoor mould has often been associated with asthma symptoms in the occupants of the affected house; ${ }^{1}$ wheeze is about twice as likely to occur in homes reported to be mouldy. ${ }^{2}$ Similar associations have been found, though less consistently, ${ }^{2}$ in studies in which mould exposure was measured objectively ${ }^{3-5}$ or assessed by a trained observer, ${ }^{6}$ or where the outcome was an index of respiratory function. ${ }^{78}$ Associations have been reported between indoor mould and peak expiratory flow rate variability in atopic children ${ }^{9}$ and mould-sensitive young adults; ${ }^{10}$ furthermore, the prevalence of mould sensitivity rises successively in groups of adults with increasingly severe asthma. ${ }^{11}$ People whose exposure to indoor Cladosporium doubles over 2 years are more likely than others to have asthma attacks. ${ }^{12}$ In a review of the epidemiological evidence, the American National Academy of Sciences concluded: "There is sufficient evidence of an association between fungal exposure and symptom exacerbation in sensitized asthmatics. Exposure may also be related to non-specific chest problems." ${ }^{13}$

These associations could be attributable to confounding factors such as socioeconomic status, lifestyle, house dust mite infestation, cold housing, reporting bias or publication bias. Clearer evidence requires a controlled trial and would inform the advice given to patients with respiratory disease. It might also assist in highlighting the need for building regulations to address the hygrothermal conditions determining mould growth.

Mould is fairly common in British houses and has been reported in $20-30 \%$ of the homes of people with asthma or recent wheeze. ${ }^{614}{ }^{15} \mathrm{~A}$ randomised controlled trial recently demonstrated improvement of asthma in American urban children consequent on a home-based multifactor environmental intervention. ${ }^{16}$ Reduction in mould exposure formed only a small part of this intervention and seems to have consisted mainly in the use of an air purifier; the benefits were largely attributed to reductions in mite and cockroach allergens.

We have conducted what we believe to be the first randomised controlled trial to investigate the relationship between indoor mould and asthma. The object of the trial was to see whether the eradication of visible mould from the houses of patients with asthma led to any improvement in their condition. The primary end point was variability in peak expiratory flow rate; secondary end points included perceived improvement in breathing, reported change in medication use, wheeze and symptoms of rhinitis and rhinoconjunctivitis.

\section{METHODS}

The participants were patients aged 3-61 years in South Wales who reported symptoms of asthma in the last 12 months and indoor mould. They were identified by means of a short screening questionnaire enquiring about asthma symptoms and indoor mould or condensation. This was sent, with an explanatory letter, to patients on the asthma registers of general practitioners, and also to participants in a survey of housing and health in the same area. Those who reported indoor mould and asthma or wheeze in the last 12 months were invited to take part; only one person was initially approached within each household. It was explained that homes would be randomly chosen for treatment, involving removal of mould and installation of a fan in the loft, with the intention of studying the effect on asthma symptoms.

The patients who agreed to participate were visited and the presence of mould was confirmed by a trained observer. A questionnaire asking about the frequency and severity of various symptoms was administered to all members of the household who reported asthma (completed by parents for 
children under 12 years of age). The questions were those of the ISAAC questionnaire, ${ }^{17}$ but they enquired about symptoms in the last 4 weeks rather than in the last 12 months, as in ISAAC. Subjects were also asked the names of any inhalers and (separately) medicines or tablets taken for wheeze or asthma during the last 4 weeks. Skin prick tests were performed for Cladosporium cladosporioides, Alternaria alternata, Penicillium notatum, Aspergillus fumigatus and other common aeroallergens. A positive response was defined as a weal at least $3 \mathrm{~mm}$ greater in diameter than that of the negative control, excluding persons who had no reaction to the positive control (histamine).

Tiny Tag Ultra (TGU-4500) data loggers (Omni Instruments, Dundee, UK), measuring air temperature and relative humidity every $30 \mathrm{~min}$, were placed in the living room and a participant's bedroom in each house for at least a week. The mean humidity in each house was then calculated as the mass of water vapour per unit mass of dry air, using the readings of the first 7 days.

A peak flow meter was left, with instructions to record peak expiratory flow rate three times every morning and evening for 2-3 weeks, when participants were also asked to record the occurrence of certain respiratory symptoms each day. The highest of the three readings was taken on each occasion; records covering $<5$ days were excluded. As an index of asthma severity, the variability in each person's airway resistance was expressed as the coefficient of variation of these values for morning and evening separately. ${ }^{9}$

Randomisation was stratified according to the built form of the houses which were classified into three categories: detached or semi-detached houses, terraced houses and flats. The households in each category were randomly allocated to an intervention or a control group by means of serially numbered sealed envelopes.

The intervention involved removal of all visible mould using a proprietary aqueous preparation (RLT Bactdet) which contains detergent and surfactant to clean the surface and a fungicide (sodium dichlorophen) to kill any remaining surface

\begin{tabular}{|c|c|c|}
\hline & $\begin{array}{l}\text { Intervention } \\
\text { group } \\
\text { (81 houses) }\end{array}$ & $\begin{array}{l}\text { Control } \\
\text { group } \\
\text { (83 houses) }\end{array}$ \\
\hline No. of subjects at baseline & $115(44 \mathrm{M}, 71 \mathrm{~F})$ & $117(49 \mathrm{M}, 68 \mathrm{~F})$ \\
\hline Mean (SD) age (years) & 26.4 (16.2) & $27.1(16.0)$ \\
\hline Current smokers & $28(25)$ & $40(34)$ \\
\hline Positive skin test to mould & $38 / 101$ (38) & $41 / 94(44)$ \\
\hline Preventer medication in last 4 weeks & $90(78)$ & $89(76)$ \\
\hline Reliever medication in last 4 weeks & $81(70)$ & $78(67)$ \\
\hline Wheeze in last 4 weeks & $85(74)$ & $95(81)$ \\
\hline \multicolumn{3}{|l|}{ Wheeze disturbs sleep: } \\
\hline Never & $47(41)$ & $35(30)$ \\
\hline Less than weekly & $18(16)$ & $31(26)$ \\
\hline At least weekly & $49(43)$ & $51(44)$ \\
\hline Wheeze limits speech & $23(20)$ & $17(15)$ \\
\hline \multicolumn{3}{|l|}{ Wheeze affects activity: } \\
\hline Not at all & $43(37)$ & $48(41)$ \\
\hline A little & $40(35)$ & $46(39)$ \\
\hline Moderately & $25(22)$ & $14(12)$ \\
\hline A lot & $7(6)$ & $9(8)$ \\
\hline Rhinitis & $74(64)$ & $71(61)$ \\
\hline Rhinoconjunctivitis & $44(38)$ & $40(34)$ \\
\hline \multicolumn{3}{|l|}{ Rhinitis affects activity: } \\
\hline Not at all & $61(54)$ & $62(53)$ \\
\hline A little & $32(28)$ & $39(34)$ \\
\hline Moderately & $15(13)$ & $10(9)$ \\
\hline A lot & $6(5)$ & $5(4)$ \\
\hline No. with any follow-up data & $95(83)$ & 87 (74) \\
\hline
\end{tabular}

Data expressed as $\mathrm{n}(\%)$ unless otherwise indicated.

Numbers do not always add up to totals because of missing data. mould. The surface was allowed to dry and another proprietary aqueous preparation (RLT Halophen) was applied which contains a fungicide (dialkyl dimethylammonium chloride) and chemical agents that aid penetration below the surface in order to kill mould hyphae in the substrate. The householders were each given a further sachet of fungicide that could be mixed with paint if they wished to repaint the affected surfaces to inhibit new growth. The control group was offered an antimould kit l year later. The fungicidal preparations were supplied by Mould Growth Consultants Ltd, Cheam, Surrey, UK. A positive input ventilation fan (Drimaster; NuAire Ltd, Caerphilly, UK) was installed in the loft to promote ventilation.

Questionnaires were administered 6 months and 12 months after randomisation, enquiring about the same symptoms and medication use as before. The answers were compared with those at baseline; for each symptom, subjects who improved or deteriorated were defined as those whose reporting of that symptom had changed, either by occurring on one occasion and not on the other, or in respect of its severity (for the three symptoms for which information on severity is available, see table 1). No attempt was made to quantify improvement and deterioration for these symptoms, since it could not be assumed that all differences between adjacent categories were comparable. In each group the net percentage who improved was calculated (the number who improved minus the number who deteriorated as a percentage of all with information on both occasions). A multilevel multinomial model, with subjects nested in households to allow for the cluster sampling, was fitted using MLwiN Version 2.01. Confidence intervals for the differences (intervention - control) between the net percentages who improved were calculated together with $\mathrm{p}$ values. Changes in the use of preventers and relievers were similarly expressed as the net percentages of those ceasing to use these inhalers, based on the numbers who had used them within the last 4 weeks at baseline but not at follow-up minus the numbers who had used them at follow-up but not at baseline.

In addition, at follow-up the subjects were asked whether their breathing was better than, the same as or worse than at baseline, and whether their medication use in the last 6 months was more than, the same as or less than it was previously ("perceived change" in medication use). Peak expiratory flow readings were made as before.

At 12 months the houses were visited again and inspected for the presence of indoor mould. Indoor temperature and humidity were measured for 7 days using the same data loggers as before.

Separate analyses of the data were made at 6 and 12 months as there were factors which might act differently at the two times. We believed that regrowth of mould was unlikely by 6 months, so the comparison would not be affected by mould reappearing in some houses. Asthma is affected by seasonal factors and, by comparing the data after 12 months with that from baseline, we could adjust for seasonality.

We planned to randomise 160 houses altogether to the intervention and control groups. We expected to recruit on average 1.5 persons per household and anticipated 10\% to be lost to follow-up. Based on estimates of the variability of the within-subject changes in the coefficient of variation, this sample was large enough to detect a difference of 1 in the change in coefficient of variation over 12 months between the intervention and control groups, given an estimate of 2.5 for the standard deviation of these changes at $80 \%$ power, allowing for a small within-household correlation. It would also give $80 \%$ power for detecting a reduction in the percentage of persons who wheeze from $70 \%$ to $50 \%$.

Ethical approval for the study was obtained from the Bro Morgannwg and Bro Taf local research ethics committees. 


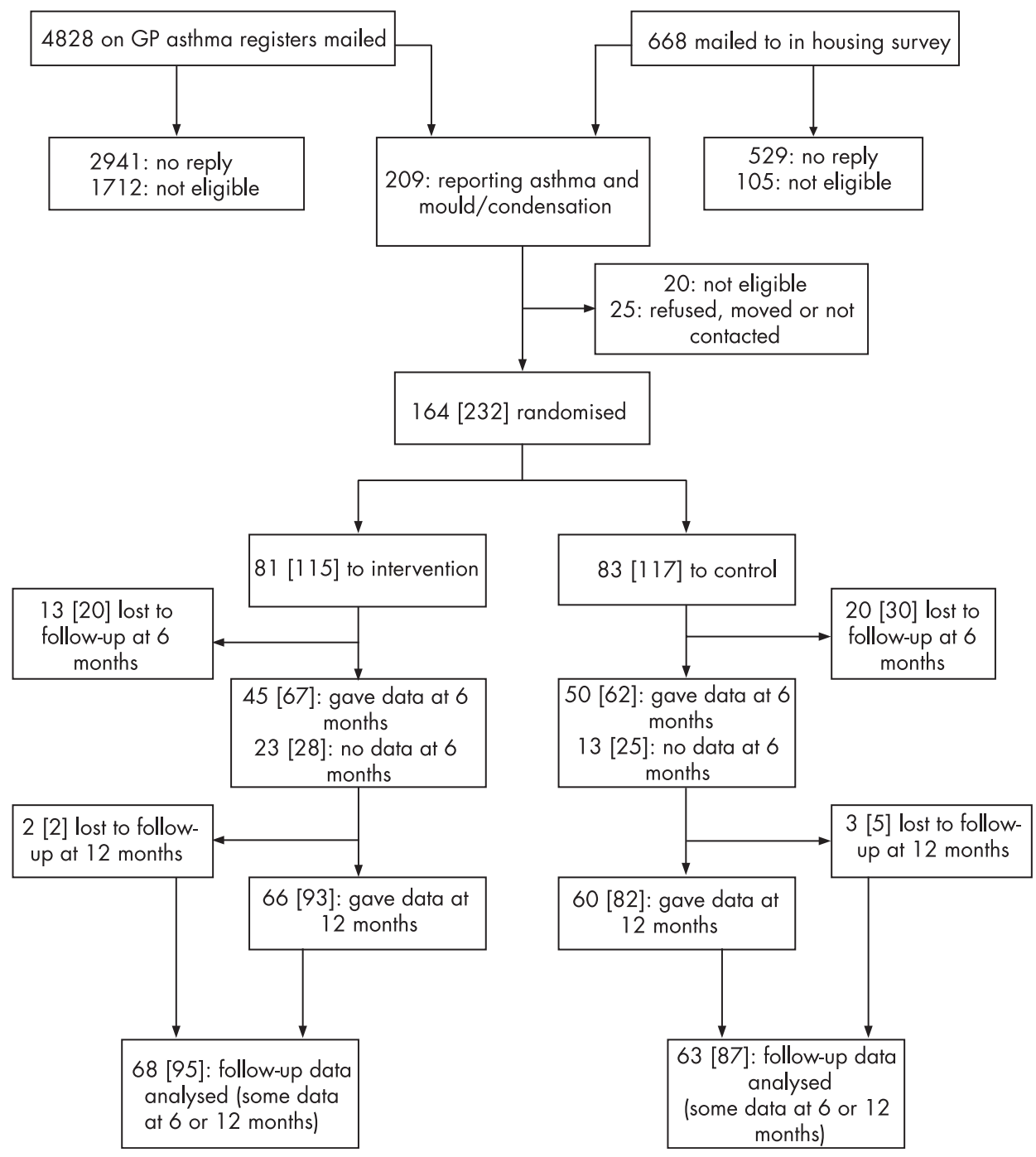

Figure 1 Trial profile. Data refer to houses; numbers of persons are shown in square brackets.

\section{RESULTS}

Initial letters and screening questionnaires were mailed to 4828 patients on general practitioners' asthma registers and to 668 other people during a survey of housing and health. Ultimately, 164 households were found to be suitable, each containing at least one patient with asthma who agreed to take part (fig 1). The patients who agreed to participate were visited and the presence of mould was confirmed by a building scientist. Details of the areas affected by mould, its distribution within houses and the genera identified have been published separately. ${ }^{18}$ Twenty-eight of the 81 households allocated to the intervention group (35\%) and 36 of the 83 control households $(43 \%)$ contained at least one person who currently smoked cigarettes.

Table 1 gives baseline data for the two groups. Patients allocated to the intervention and control groups were broadly similar, particularly in respect of the occurrence and severity of wheeze and rhinitis and recent use of preventer medication (inhaled corticosteroids and a few long acting $\beta_{2}$ agonists) and relievers ( $\beta_{2}$ agonists and a few antimuscarinic inhalers).

Some follow-up information (questionnaires or peak expiratory flow data) was obtained from 95 participants in 68

Table 2 Changes in variability of peak expiratory flow rate (PEFR)

\begin{tabular}{|c|c|c|c|c|c|c|c|c|c|c|c|}
\hline \multirow[b]{2}{*}{ Group } & \multicolumn{3}{|c|}{ Baseline } & \multicolumn{3}{|c|}{ Change $0-6$ months } & \multirow{2}{*}{$\begin{array}{l}\text { Difference } \\
(95 \% \mathrm{CI})^{*}\end{array}$} & \multicolumn{3}{|c|}{ Change 0-12 months } & \multirow{2}{*}{$\begin{array}{l}\text { Difference } \\
(95 \% \mathrm{Cl})^{*}\end{array}$} \\
\hline & $\mathbf{N}$ & Mean & SD & $\mathrm{N}$ & Mean & SD & & $\mathrm{N}$ & Mean & SD & \\
\hline \multicolumn{12}{|c|}{ CV of morning PEFR } \\
\hline Intervention & 107 & 7.85 & 5.75 & 41 & -0.42 & 4.44 & $1.59(-0.40$ to 3.58$)$ & 82 & -1.62 & 6.47 & $0.46(-1.58$ to 2.50$)$ \\
\hline Control & 104 & 8.55 & 5.23 & 43 & -2.01 & 4.71 & & 66 & -2.08 & 5.96 & \\
\hline \multicolumn{12}{|c|}{ CV of evening PEFR } \\
\hline Intervention & 107 & 7.00 & 5.09 & 41 & -1.59 & 4.61 & $0.21(-1.90$ to 2.31$)$ & 82 & -1.30 & 6.04 & $1.42(-0.58$ to 3.43$)$ \\
\hline Control & 104 & 8.04 & 5.67 & 42 & -1.80 & 5.02 & & 67 & -2.72 & 6.30 & \\
\hline
\end{tabular}

$\mathrm{CV}$, coefficient of variation.

${ }^{*}$ Difference $=$ change in intervention group minus change in control group. 
Table 3 Net improvement in intervention and control groups at 6 months

\begin{tabular}{|c|c|c|c|c|c|c|c|c|c|}
\hline & \multicolumn{4}{|c|}{ Intervention group } & \multicolumn{4}{|c|}{ Control group } & \multirow[b]{2}{*}{$\begin{array}{l}\text { Difference in net \% } \\
\text { better }(95 \% \mathrm{Cl})^{*}\end{array}$} \\
\hline & Total & No. better & No. worse & $\begin{array}{l}\text { Net } \% \\
\text { better }\end{array}$ & Total & No. better & No. worse & $\begin{array}{l}\text { Net } \% \\
\text { better }\end{array}$ & \\
\hline Breathing since baseline & 67 & 39 & 4 & 52 & 58 & 12 & 12 & 0 & $52(30$ to 74$)$ \\
\hline Medication in last 6 months $†$ & 66 & 36 & 9 & 41 & 59 & 7 & 17 & -17 & 59 (35 to 81$)$ \\
\hline Preventer in last 4 weeks & 67 & 18 & 6 & 18 & 61 & 6 & 7 & -2 & 20 (2 to 37$)$ \\
\hline Reliever in last 4 weeks & 67 & 10 & 3 & 10 & 61 & 8 & 3 & 8 & $2(-12$ to 17$)$ \\
\hline Wheeze in last 4 weeks & 67 & 15 & 7 & 12 & 61 & 7 & 5 & 3 & $9(-9$ to 26$)$ \\
\hline Wheeze disturbs sleep & 67 & 25 & 6 & 28 & 61 & 19 & 11 & 13 & $15(-7$ to 38$)$ \\
\hline Wheeze limits speech & 65 & 13 & 1 & 19 & 61 & 7 & 3 & 7 & $12(-2$ to 26$)$ \\
\hline Wheeze affects activities & 67 & 27 & 6 & 31 & 61 & 15 & 11 & 7 & 25 (3 to 47$)$ \\
\hline Rhinitis & 65 & 15 & 7 & 12 & 61 & 9 & 6 & 5 & $7(-11$ to 26$)$ \\
\hline Rhinoconjunctivitis & 65 & 15 & 8 & 11 & 61 & 6 & 9 & -5 & $16(-3$ to 35$)$ \\
\hline Rhinitis affects activities & 65 & 16 & 10 & 9 & 61 & 18 & 12 & 10 & $-1(-23$ to 22$)$ \\
\hline
\end{tabular}

${ }^{*}$ Difference $=$ value in intervention group minus value in control group.

†Perceived change in medication use in last 6 months compared with use before then.

For medication, preventers and relievers, "better" and "worse" denote less and more use respectively.

intervention houses and from 87 participants in 63 control houses. In these houses, 21 intervention households and 18 control households each contained two of these participants, and three households in each group contained three; the other houses each contained one participant who provided follow-up information. Among the intervention and control participants for whom some follow-up data were obtained, 27 (28\%) and 20 $(23 \%)$, respectively, were aged $<12$ years at baseline so their questionnaires were completed by their parents.

At 6 months, data were obtained from 67 intervention and 62 control patients (58\% and $53 \%$ respectively of those enlisted); the response rates were rather low because staff were concurrently recruiting new participants. Those who provided no follow-up information at this stage were fairly similar to the whole groups into which they had been initially randomised with respect to various baseline characteristics. Of those in the intervention group who did not provide data at 6 months, the mean age was 25.2 years, $25 \%$ (12/48) were current smokers and $60 \%(12 / 20)$ at baseline had wheezed during the previous 4 weeks; in the control group the mean age was 25.2 years, $35 \%$ (19/54) were smokers and 90\% (27/30) reported recent wheeze. At 12 months some information was obtained from more people in each group $(93(81 \%)$ of the original recruits in the intervention group and $82(70 \%)$ in the control group); those not seen had similar baseline characteristics to those who were seen.

The fan was not installed in one house and we do not know how many residents used the contents of the sachet. At
12 months, 67 intervention houses and 59 control houses were inspected: $27(40 \%)$ and $46(78 \%)$, respectively, were seen to contain mould (difference 38\% (95\% confidence interval (CI) 21 to 52$) ; p<0.0001)$. In only five intervention houses had mould reappeared on the treated surfaces; in the other houses in this group the new mould growth occurred on surfaces that were previously unaffected.

At 6 months and 12 months in both the intervention and control groups the variability in the morning and evening peak expiratory flow rate readings tended to decline. The changes were greater in the control group than in the intervention group, although not significantly so (table 2 ). The daily symptom records were filled in erratically; the data did not appear to be reliable and were therefore not analysed.

After 6 months in the study there was a net improvement in breathing in $52 \%$ of those in the intervention group and $0 \%$ in the control group (table 3); this difference was highly significant $(p<0.0001)$. The perceived changes in medication use amounted to a net decrease of $41 \%$ in the intervention group and a net increase of $17 \%$ in the controls $(p<0.0001)$. Comparison of the questionnaire responses with those at baseline showed a greater tendency for all chest symptoms (particularly the more severe symptoms) to improve in the intervention group than in the controls, and this was statistically significant for wheeze that affects daily activities $(\mathrm{p}=0.028)$. Regarding treatment in the previous 4 weeks, table 3 shows the numbers of people in each group whose use of preventers and relievers changed between baseline and

Table 4 Net improvement in intervention and control groups at 12 months

\begin{tabular}{|c|c|c|c|c|c|c|c|c|c|}
\hline & \multicolumn{4}{|c|}{ Intervention group } & \multicolumn{4}{|c|}{ Control group } & \multirow[b]{2}{*}{$\begin{array}{l}\text { Difference in net \% } \\
\text { better }(95 \% \mathrm{Cl})^{*}\end{array}$} \\
\hline & Total & No. better & No. worse & $\begin{array}{l}\text { Net } \% \\
\text { better }\end{array}$ & Total & No. better & No. worse & $\begin{array}{l}\text { Net } \% \\
\text { better }\end{array}$ & \\
\hline Breathing since baseline & 86 & 50 & 5 & 52 & 76 & 24 & 6 & 24 & 29 (10 to 47$)$ \\
\hline Medication in last 6 months $†$ & 89 & 33 & 13 & 22 & 79 & 29 & 16 & 16 & $6(-15$ to 27$)$ \\
\hline Preventer in last 4 weeks & 90 & 24 & 11 & 14 & 81 & 6 & 10 & -5 & $19(4$ to 35$)$ \\
\hline Reliever in last 4 weeks & 90 & 25 & 7 & 20 & 81 & 9 & 7 & 2 & $18(2$ to 33$)$ \\
\hline Wheeze in last 4 weeks & 89 & 22 & 7 & 17 & 81 & 20 & 4 & 20 & $-3(-19$ to 12$)$ \\
\hline Wheeze disturbs sleep & 89 & 30 & 10 & 22 & 81 & 35 & 4 & 38 & $-16(-34$ to 2$)$ \\
\hline Wheeze limits speech & 87 & 11 & 1 & 11 & 81 & 6 & 3 & 4 & $8(-2$ to 18$)$ \\
\hline Wheeze affects activities & 90 & 36 & 11 & 28 & 81 & 30 & 12 & 22 & $5(-15$ to 26$)$ \\
\hline Rhinitis & 90 & 22 & 6 & 18 & 81 & 7 & 12 & -6 & $24(9$ to 39$)$ \\
\hline Rhinoconjunctivitis & 90 & 21 & 7 & 16 & 81 & 8 & 12 & -5 & $20(5$ to 36$)$ \\
\hline Rhinitis affects activities & 90 & 28 & 17 & 12 & 81 & 17 & 18 & -1 & $13(-7$ to 33$)$ \\
\hline
\end{tabular}

${ }^{*}$ Difference $=$ value in intervention group minus value in control group.

†Perceived change in medication use in last 6 months compared with use before then.

For medication, preventers and relievers, "better" and "worse" denote less and more use respectively. 
6 months, together with the net trends. There was a significantly greater tendency to cease taking preventers in the intervention group than in the control group $(p=0.033)$; for relievers, the net trends $(8-10 \%$ reductions) in the two groups were very similar.

At 12 months, the net improvement in breathing reported by the intervention group was still significantly greater than that of the control group $(p=0.001)$, although the controls had improved substantially from baseline (table 4). Compared with baseline, use of inhaled corticosteroids and other preventive medication in the previous 4 weeks showed net trends of $14 \%$ ceasing and 5\% starting in the intervention and control groups, respectively, and net trends away from reliever use of $20 \%$ (intervention) and 2\% (control). In each case the difference between the groups was statistically significant $(p=0.017$ for preventers and 0.023 for relievers).

The differences regarding chest symptoms were less consistent than at 6 months, but significant differences appeared in the improvement of symptoms of rhinitis $(p=0.001)$ and rhinoconjunctivitis $(p=0.009)$. There was some evidence, although not statistically significant, of greater improvement in those intervention houses in which mould did not reappear compared with those where it did. For example, of 52 people in houses where mould did not reappear, 17 improved with regard to their rhinitis and 5 deteriorated compared with 5 and 1 , respectively, of 38 in houses where it reappeared. There were no clear differences between those with and without positive skin tests to mould.

Indoor temperature and humidity were measured both at baseline and at 12 months in 64 intervention houses and 58 control houses. At baseline the mean (SD) humidity was 8.67 (1.28) $\mathrm{g} / \mathrm{kg}$ in the intervention houses and 8.51 (1.54) $\mathrm{g} / \mathrm{kg}$ in the control houses; at 12 months it was 8.44 (1.67) g/kg and $8.76(1.49) \mathrm{g} / \mathrm{kg}$, respectively. The difference between these changes $(0.48 ; 95 \%$ CI 0.11 to 0.85$)$ was statistically significant $(\mathrm{p}=0.011)$.

\section{DISCUSSION}

We believe that this is the first randomised controlled trial to investigate experimentally the relationship between indoor mould and asthma. It provides evidence that eradicating visible mould benefits patients by improving symptoms of asthma and rhinitis and enabling them to reduce their medication.

Most of the participants were drawn from general practitioners' asthma registers, so that their asthma had been diagnosed by a doctor at some time. They had all had symptoms of asthma during the 12 months before recruitment. Visible indoor mould was eradicated in all houses in the intervention group but 12 months later it had reappeared (mostly at new sites) in $40 \%$ of these dwellings. Some members of the control group took their own action to remove mould so that by 12 months it was present in only $78 \%$ of control houses. The difference in mould exposure between the two groups therefore diminished over time (100\% initially and 38\% at 12 months). This may explain why the effects on chest symptoms were less consistent at 12 months than at 6 months. The effect on rhinitis and rhinoconjunctivitis may have been more evident at 12 months because of the seasonal nature of these conditions in many people, the questionnaire being completed at the same time of year as before.

Variability in peak expiratory flow, expressed as the coefficient of variation of these readings (an index of asthma severity associated with indoor mould in another study), ${ }^{9}$ declined in both morning and evening. Although these changes were greater in the control group (contrary to our prior hypothesis), the differences between the groups were not statistically significant so they may have been chance effects.
The tendency in both groups for asthma to improve over time was probably due to regression to the mean occurring when patients with a variable disease are selected because of current symptoms. This improvement accompanied a much greater perceived reduction in medication use in the intervention group than in the controls-a difference of 59\% at 6 months when the intervention group also showed a greater reduction in symptoms despite a decline (not occurring among the controls) in their use of inhaled corticosteroids. At 12 months, although the effects on symptoms were less clear, there were greater reductions in both preventer and reliever use in the intervention group than in the controls. Thus, the intervention appeared to reduce medication and improve symptoms (consistent with previous evidence), but without a corresponding effect on an objective index of asthma severity. Patients in both groups probably adjusted their medication use to maintain good airflow.

One weakness of this study was the follow-up rate, which was particularly low at 6 months. The follow-up data were therefore potentially subject to selection bias. The response rates were similar in the intervention and control groups, and the participants who were seen and those who were not seen had similar baseline characteristics. Thus, differential bias did not seem to have occurred, although it cannot be entirely ruled out.

Another important weakness is the possibility of a placebo effect. With this type of intervention (and that of the American multifactor environmental trial), ${ }^{16}$ it was not possible to blind the participants to their allocation in the trial. They inevitably knew whether the mould had been removed or not, so there was clearly scope for a placebo effect, especially with the questions on breathing and medication which asked the participants whether they had changed since a previous occasion. The only objective data (peak expiratory flow rate variability) showed no significant difference between the groups; concurrently collected data on daily bronchodilator use would have been useful evidence on actual changes in treatment.

There are some reasons, however, for believing that a placebo effect is not the whole explanation for the different outcomes of the two groups. First, the improvement in breathing reported by participants was borne out by their answers to the same questions about wheeze on different occasions; it is unlikely that people remembered how they had responded to these questions at baseline after an interval of 6 months, when all the wheeze symptoms improved more in the intervention group than in the controls. Second, the decline in medication, which in the first 6 months occurred in the use of preventers by the intervention group, was not reversed during the following 6 months when a placebo effect would be expected to have worn off, but was extended to their use of relievers. Third, there is some evidence of a larger effect of the intervention in the houses where there was no mould at 12 months than in those where mould was found then. Although the difference was not significant, this is consistent with a real effect. Finally, the trial was presented to the participants as a study of asthma and chest health; no expectations were raised as to any effects on the nose or eyes. The reduction in the symptoms of rhinitis and rhinoconjunctivitis, consistent with published evidence of an association with indoor mould, ${ }^{9}$ is therefore unlikely to represent a placebo effect. Thus, although reporting bias cannot be ruled out, the results suggest a beneficial effect of mould eradication.

Mould sensitivity was detected in $41 \%$ of the participants of this trial using skin tests for four moulds. There is good reason to believe that more mould-sensitive patients would be detected by testing against a greater number of fungal antigens and by 
conducting specific anti-IgE RAST blood tests. ${ }^{19}$ This may explain the lack of any clear greater benefit of the intervention in those patients who were known to be mould-sensitive. Furthermore, the benefits of mould eradication may not be limited to reducing allergen exposure in mould-sensitive persons. Moulds emit mycotoxins and other volatile compounds that can irritate mucous membranes and thus provoke asthma and rhinoconjunctivitis. ${ }^{20} 21$ There may also be effects on the immune system; an association has been reported between heavy exposure to indoor mould and chronic stimulation of lymphocytes in children..$^{22}$ A recent community survey in Norway showed indoor moulds to be associated with a wide range of respiratory symptoms. ${ }^{23}$

It is difficult to judge how far our participants represent the generality of patients with asthma who live in houses affected by mould, given the low response rate $(37 \%)$ to the screening questionnaire. There were no gross differences between those who dropped out after randomisation and those from whom they were derived, so selective bias does not seem to have operated at that stage.

We cannot assess the relative contributions of mould removal, fungicide application and improved ventilation to these results. The fungicides appeared to prevent mould regrowth and the fan reduced atmospheric humidity, but we do not know what would have happened if each element of the intervention had been omitted. A further improvement in ventilation might produce a greater reduction in mould growth, although it would be offset by loss of heat in cold weather.

The results of this trial are not entirely conclusive, in view of the absence of objective evidence of benefit. Nevertheless, they suggest that patients with asthma and rhinitis would be well advised to remove mould from their homes. Asthma control tends to be based largely on medication. Useful environmental measures have been limited to the avoidance of cigarette smoke and sources of certain allergens (such as cats), and attempts to reduce mite exposure have been somewhat ineffective. ${ }^{24}$ The eradication of visible mould is a fairly simple procedure that should receive greater attention, particularly in houses inhabited by people with severe asthma, since fungal sensitivity is a powerful risk factor for this condition. ${ }^{11}{ }^{19}$ Mould removal and the application of a fungicide wash need to be repeated as necessary, since mould tends to reappear at new sites within 12 months.

\section{ACKNOWLEDGEMENTS}

The authors thank the general practitioners who allowed them to contact their patients, and Neath and Port Talbot County Borough Council who collaborated in the Housing and Neighbourhoods and Health (HANAH) project.

\section{Authors' affiliations}

M L Burr, I P Matthews, R A Arthur, H L Watson, C J Gregory,

F D J Dunstan, S R Palmer, Department of Epidemiology, Statistics and Public Health, Cardiff University, Cardiff, UK
Funding was received from Asthma UK (grant number 01/025), the Medical Research Council (grant number G9900679) and the Welsh Office of Research and Development (grant number S01/001).

Competing interests: None declared.

\section{REFERENCES}

1 Burr ML. Health effects of indoor molds. Rev Environ Health 2001;16:97-103.

2 Strachan DP. The role of environmental factors in asthma. Br Med Bull 2000;56:865-82.

3 Strachan DP, Flannigan B, McCabe EM, et al. Quantification of airborne moulds in the homes of children with and without wheeze. Thorax 1990;45:382-7.

4 Verhoeff AP, van Wijnen JH, van Reenen-Hoekstra ES, et al. Fungal propagules in house dust. II. Relation with residential characteristics and respiratory symptoms. Allergy 1994;49:540-7.

5 Garrett MH, Rayment PR, Hooper MA, et al. Indoor airborne fungal spores, house dampness and associations with environmental factors and respiratory health in children. Clin Exp Allergy 1998;28:459-67.

6 Williamson IJ, Martin CJ, McGill G, et al. Damp housing and asthma: a casecontrol study. Thorax 1997;52:229-34.

7 Brunekreef B, Dockery DW, Speizer FE, et al. Home dampness and respiratory morbidity in children. Am Rev Respir Dis 1989;140:1363-7.

8 Zock J-P, Jarvis D, Luczynska C, et al. Housing characteristics, reported mold exposure, and asthma in the European Community Respiratory Health Survey. J Allergy Clin Immunol 2002;110:285-92.

9 Andriessen JW, Brunekreef B, Roemer W. Home dampness and respiratory health status in European children. Clin Exp Allergy 1998;28:1191-200.

10 Dharmage S, Vailey M, Raven J, et al. Mouldy houses influence symptoms of asthma among atopic individuals. Clin Exp Allergy 2002;32:714-20.

11 Zureik M, Neukirch C, Leynaert B, et al. Sensitisation to airborne moulds and severity of asthma: cross sectional study from European Community respiratory health survey. BMJ 2002;325:411-4.

12 Matheson MC, Abramson MJ, Dharmage SC, et al. Changes in indoor allergen and fungal levels predict changes in asthma activity in young adults. Clin Exp Allergy 2005;35:907-13.

13 National Academy of Sciences Institute of Medicine. Clearing the air: asthma and indoor air exposures. Washington: National Academic Press, 2000.

14 Burr ML, Mullins J, Merrett TG, et al. Indoor moulds and asthma. J R Soc Health 1988;108:99-101.

15 Strachan DP. Damp housing and childhood asthma: validation of reporting of symptoms. BMJ 1988;297:1223-6.

16 Morgan WJ, Crain EF, Gruchalla RS, et al. Results of a home-based environmental intervention among urban children with asthma. N Engl J Med 2004;351:1068-80.

17 ISAAC Steering Committee. Phase One Manual, 2nd edn. Auckland, New Zealand and Munster, Germany: ISAAC International Centre, 1993.

18 Arthur RA, Gregory CJ, Matthews IP. The amount of surface mould contamination in homes in South Wales and the prevalence and relative abundance of differing mould genera. In: de Oliveira Fernandes E, Gameiro da Silva M, Rosado Pinto J, eds. Healthy buildings 2006: creating a healthy indoor environment for people, Proceedings of International Society of Indoor Air Quality and Climate, Vol II, 4-8 June 2006, Lisbon, 2006:325-8.

19 Denning DW, O'Driscoll BR, Hogaboam CM, et al. The link between fungi and severe asthma: a summary of the evidence. Eur Respir J 2006;27:615-26.

20 Flannigan B, McCabe EM, McGarry F. Allergenic and toxigenic microorganisms in houses. J Appl Bacteriol Symposium Suppl 1991;70:61-73S

21 Kilburn KH. Indoor mold exposure associated with neurobehavioral and pulmonary impairment: a preliminary report. Arch Environ Health 2003;58:390-8.

22 Dales R, Miller D, White J, et al. Influence of residential fungal contamination on peripheral blood lymphocyte populations in children. Arch Environ Health 1998;53:190-5.

23 Skorge DT, Eagan TML, Eide GE, et al. Indoor exposures and respiratory symptoms in a Norwegian community sample. Thorax 2005;60:937-42.

24 Gøtzsche PC, Johansen HK, Schmidt LM, et al. House dust mite control measures for asthma. In:Cochrane Library. Issue 4. Oxford: Update Software, 2004.

\section{Access a vast information database with Toll-Free linking}

"Toll-free" linking gives you immediate access to the full text of many of the cited articles in a paper's reference list-FOR FREE. With the support of HighWire's vast journal catalogue, a huge reference library is now open to you. If HighWire hosts the journal, you can view the full text of the referenced article, completely free of charge by following the Free Full Text links in the references. 